\title{
BMJ Open Changes in medical use of central nervous system stimulants among US adults, 2013 and 2018: a cross- sectional study
}

\author{
Thomas J Moore (1) , ${ }^{1,2}$ Phillip W Wirtz, ${ }^{3}$ Stefan P Kruszewski, ${ }^{1}$ \\ G Caleb Alexander ${ }^{1,4}$
}

To cite: Moore TJ, Wirtz PW, Kruszewski SP, et al. Changes in medical use of central nervous system stimulants among US adults, 2013 and 2018: a crosssectional study. BMJ Open 2021;11:e048528. doi:10.1136/ bmjopen-2020-048528

- Prepublication history for this paper is available online. To view these files, please visit the journal online (http://dx.doi. org/10.1136/bmjopen-2020048528).

Received 30 December 2020 Accepted 26 July 2021

Check for updates

(c) Author(s) (or their employer(s)) 2021. Re-use permitted under CC BY-NC. No commercial re-use. See rights and permissions. Published by BMJ.

${ }^{1}$ Center for Drug Safety and Effectiveness, Johns Hopkins University Bloomberg School of Public Health, Baltimore, Maryland, USA

${ }^{2}$ Department of Epidemiology, The George Washington University Milken Institute of Public Health, Washington, District of Columbia, USA ${ }^{3}$ Department of Decision Sciences, The George Washington University School of Business, Washington, DC, USA

${ }^{4}$ Divison of General Internal

Medicine, Johns Hopkins

Medicine, Baltimore, Maryland, USA

Correspondence to

Mr Thomas J Moore;

tmoore86@jhmi.edu

\section{ABSTRACT}

Objective To assess the 5-year changes in the adult medical use of central nervous system (CNS) stimulants with higher risk of dependence and evaluate the population characteristics of users and their medical and/ or neurological conditions.

Design Cross-sectional study.

Setting Annual US Medical Expenditure Panel Survey, a stratified random sample of approximately 30000 persons designed to produce national population estimates. It focuses on reported medical spending, medical services used, health status and prescription medications.

Participants Adults age 19 years and older who reported obtaining one or more prescriptions for amphetamine or methylphenidate products during two survey years, 2013 and 2018.

Main outcomes measures Prescriptions obtained, the specific stimulant product and annual treatment days of drug supplied.

Results In 2018, an estimated 4.1 million US adults (95\% Cl 3.4 million to 4.8 million) reported prescriptions for CNS stimulants, having filled a mean of $7.3(95 \% \mathrm{Cl} 6.8$ to 7.8$)$ prescriptions with a mean of 226 (95\% Cl 210 to 242) days' supply. Compared with 2013, the estimated number of adults reporting using CNS stimulants in 2018 increased by 1.8 million (95\% Cl 1.0 million to 2.7 million) or $79.8 \%$. Most 2018 adult stimulant users reported taking psychoactive medication for one or more mental, behavioural or neurodevelopment disorders. Overall, $77.8 \%$ (95\% Cl 72.6\% to $83.0 \%$ ) reported some medication for adult attention deficit disorder, $26.8 \%(95 \% \mathrm{Cl} 22.2 \%$ to $31.5 \%)$ took medication for anxiety, $25.1 \%(95 \% \mathrm{Cl} 19.9 \%$ to $30.3 \%)$ for depression and $15.3 \%$ (95\% Cl 9.8\% to $20.8 \%$ ) indicated drug treatment for other mental or neurological disorders. Adult CNS stimulant use was higher in females, in younger age cohorts and among individuals of white race/ethnicity. Conclusions Adult medical use of prescription stimulants increased markedly in 5 years and occurred in a population often reporting multiple mental or neurological disorders. Further action is needed to understand and manage this new resurgence in drugs with high risks of dependence.

\section{INTRODUCTION}

The central nervous system (CNS) stimulants amphetamine and methylphenidate
Strengths and limitations of this study

- This analysis of adult use of prescription amphetamine and methylphenidate stimulants is based on the largest publicly available annual US health survey conducted annually since 1996 .

- While the utilisation of these stimulant drug products in 2013 and 2018 was self-reported in an annual household survey, the prescription detail was confirmed in pharmacy records.

- The annual, federally funded survey was designed to support health policy analysis; its multistage probability design supports population estimates and Cls for the entire US population.

- With an overall survey random sample of approximately 30000 households and 325000 dispensed prescriptions for each year, the number of cases indicating the study drug products was modest.

- Given stimulant drugs with a higher risk of psychological or physical dependence, as well as risks of non-medical use, the self-reporting feature of this survey could result in underestimating actual exposure among adults.

are among the oldest synthetic psychoactive medications still in widespread clinical use. The amphetamine product Benzedrine was first marketed in 1933 for nasal congestion and in 1937 for depression and narcolepsy'; in 1954, the US Food and Drug Administration (FDA) approved a methylphenidate product (Ritalin), which was marketed for depression, senile behaviour, lethargy and narcolepsy. ${ }^{2}$

Amphetamine and methylphenidate are potent and structurally related sympathomimetic amines with therapeutic mechanisms that remain unclear but stimulate the release of dopamine and norepinephrine primarily through inhibition of neuronal reuptake. ${ }^{3}$ Currently, a large number of amphetamine products are licenced based on mixtures of various salts (saccharate, sulfate and 
aspartate), specific enantiomers (d-), extended release formulations and a prodrug. Methylphenidate has fewer chemical variants but is available in immediate and extended release formulations, d-enantiomer salt mixtures and a transdermal patch. Multiple generics and brand name variants are available for both stimulants. Approved and off-label uses of these two CNS stimulants have evolved over the many decades. Medical use for depression and weight loss declined in the 1950s and 1960 s, and these indications were repealed over concern about growing evidence of misuse and questions about effectiveness. ${ }^{1}$ However, beginning in 1961, use in children expanded with FDA approval of indications for treating behavioural problems and later for attention deficit hyperactivity disorder (ADHD). ${ }^{4}$ For many years, new formulations were approved based on studies of ADHD in children. Starting in 2004, the FDA extended the ADHD indication to adults for some branded stimulants (Adderall XR, Concerta, Vyvanse) and in 2015 approved a binge eating indication for lisdexamfetamine (Vyvanse).$^{5-7}$ Throughout the decades since initial marketing, the two stimulant products were approved for narcolepsy, and during that time, off-label use was observed among persons using them to increase alertness or seeking to achieve cognitive enhancement. ${ }^{8}$

Amphetamine and methylphenidate have been long restricted globally because of addiction risks including a United Nations Convention on Psychotropic Substances and specific legal controls in many countries, including the UK, Canada and Australia. ${ }^{9-12}$ In the USA, these stimulants are classified as Schedule II Controlled Substances, those declared to have 'a high potential for abuse which may lead to severe psychological or physical dependence'. ${ }^{13}$ Other major Schedule II drugs include higher potency opioids and the barbiturates. Restrictions for this highest risk class of licit psychoactive drugs include a Drug Enforcement Administration licence to prescribe, limitations on prescribed refills, monitoring at the state and federal levels and secure pharmacy storage measures to prevent theft and diversion. In addition to risks of misuse and dependence, other adverse events associated with these stimulants include serious cardiovascular reactions, seizures, tics, tremors, aggression, manic symptoms and psychosis. ${ }^{5-714}$ Given that the increased use of prescription opioids continued for many years before declining in response to numerous public health initiatives, we examined the most recent trends in exposure to the other widely used group of Schedule II drugs: the CNS stimulants amphetamine and methylphenidate.

\section{METHODS}

We extracted the data for this study from the US Medical Expenditure Panel Survey (MEPS), a healthcare survey of individuals and households conducted annually since 1996 and published for research use by the Agency for Healthcare Research and Quality. ${ }^{15}$ To assess change over 5 years, this study analysed the 2013 and 2018 annual surveys. MEPS collects data from a nationally representative sample of approximately 30000 persons each year, and its multistage probability design supports estimates and variance of the US population. The confidentiality of personal identifying information is protected by federal law and removed before survey data are released for public research use. ${ }^{16}$ These deidentified public use data are exempt from review by the Johns Hopkins Bloomberg School of Public Health Institutional Review Board.

\section{Identification of medications}

Population estimates of exposure to prescription drugs in MEPS begin with the household survey questionnaire and are then expanded with more detailed information collected from respondents' pharmacies. ${ }^{17}$ Each annual data release contains a prescribed medicines file with records for approximately 325000 prescriptions and multiple fields identifying the drug prescription detail. We used the following algorithm to standardise medications: if the record contained a National Drug Code (NDC), we matched it to the ingredient name in the National Library of Medicine RxNorm database ${ }^{18}$; for prescription records without an NDC, we used the Multum Lexicon medication name, which is defined as the generic name most commonly used by physicians. ${ }^{17}$ Medication names provided by respondents that were vague or described a class of drugs (eg, stimulants and antidepressants) were excluded. The outpatient medications identified by survey respondents were then confirmed in pharmacy records, which also provided additional detail about each dispensed prescription for the survey year. ${ }^{19}$

For this study, we identified persons reporting any use of the following standardised generic medication names: amphetamine/dextroamphetamine, lisdexamfetamine, methylphenidate and dexmethylphenidate. Notably, lisdexamfetamine and dexmethylphenidate are newer brand name drugs without generics. Amphetamine/ dextroamphetamine and methylphenidate describe multiple generic products. The objective of analysing the two newer brand name products separately was to measure any effects of marketing and promotion, as compared with generics. We excluded CNS stimulants that were not classified as Schedule II (eg, atomoxetine), or those with utilisation that was too infrequent to estimate in the MEPS data (prescription methamphetamine). The extent of each respondent's exposure was measured by calculating the number of prescriptions filled in the survey year and the total annual days' supply reported for these prescriptions. If the days' supply was missing for a prescription, we imputed the days' supply based on median days supply for that drug (eg, lisdexamfetamine) among respondents with non-missing values. For some analyses, we also combined the four products into these two groups: amphetamine and methylphenidate products.

This study population included all persons reporting that they were 19 years of age or older as last ascertained during the survey year. Other assessed population 
characteristics included sex, race/ethnicity, education and marital status. Among those reporting exposure to Schedule II CNS stimulants, we also analysed the mental health, neurological or developmental conditions for which respondents indicated one or more of the following: (1) they had the condition during the survey year; (2) they took a prescribed medication for the condition; and (3) they received medical treatment, defined as an office, outpatient, inpatient or emergency department visit. The mental health conditions analysed were identified by the following International Classification of Disease, 10th Revision (ICD-10) codes: ADHD (F90), major depression (F32), anxiety (F40 and F41) and other neurological or mental conditions (all other ICD-10 codes in the ' $\mathrm{F}$ ' series). The mental health condition information in the ICD-10 coding format was not available for the year 2013, limiting this analysis to the 2018 survey year data.

\section{Statistical analysis}

We estimated the exposed adult population totals, percentages and 95\% CIs using the MEPS multistage probability design characteristics for the entire US population in accordance with the survey statistical methods documentation. ${ }^{20}$ Each survey observation included data on the sampling unit, the sampling stratum and the specific sample weight for each observation. Populations, variance and statistical significance within survey years were estimated using Taylor series linearisation. SEs and CIs were calculated based on the weighted estimates when available. A Z-test of two binomial proportions was used to compare the proportions across years. All analyses were performed using SAS V9.4 (SAS Institute) and were conducted from July to October 2020.

\section{Public and patient involvement}

The public/patients were not involved in the design, conduct or reporting of this study.

\section{RESULTS}

\section{Stimulant population characteristics}

In 2018, an estimated 4.1 million US adults (95\% CI 3.4 million to 4.8 million) reported that they had filled one or more prescriptions for the CNS stimulants amphetamine or methylphenidate. Population characteristics are shown in table 1 . Use of these prescription stimulants skewed towards the younger age cohorts, and the percentage reporting prescription use was highest among those age $19-24$ years- $3.2 \%$ (95\% CI $1.7 \%$ to $4.8 \%$ )and lowest among those age $65-85$ years- $0.5 \%(95 \%$ CI $0.3 \%$ to $0.7 \%$ ). Utilisation also varied substantially by race/ethnicity with $2.3 \%$ (95\% CI $1.8 \%$ to $2.8 \%$ ) of whites reporting use compared with $0.6 \%$ (95\% CI $0.3 \%$ to $1.0 \%$ ) of blacks, a nearly fourfold difference. CNS stimulant use was also higher in those with education beyond high school and among those never married compared with those currently or previously married.

\section{CNS stimulant medication use}

In 2018, US adults filled an estimated 30.2 million prescriptions (95\% CI 27.9 million to 32.4 million) for CNS stimulants. Medication detail is shown in table 2. These adults filled a mean of 7.3 (95\% CI 6.8 to 7.8 ) prescriptions during the survey year, which provided a mean of 226 (95\% CI 210 to 242) days' supply. Amphetamine products were more widely used among adults than methylphenidate products, accounting for $78.9 \%$ versus $21.1 \%$ of the 2018 prescription volume.

\section{Change in utilisation}

Reported use of these CNS simulants increased during the 5 years from the 2013 to the 2018 annual MEPS survey. Survey-to-survey changes are shown in table 3 . The estimated number of adults increased from 2.3 million $(95 \%$ CI 1.8 million to 2.8 million) in 2013 to 4.1 million (95\% CI 3.4 million to 4.8 million) in 2018. During that period, adult exposure increased by an estimated 1.8 million adults $(\mathrm{t}=4.35, \mathrm{p}<0.01)$ or an increase of $79.8 \%$. Examined by sex, the largest increase occurred among females, who accounted for 1.3 million of 1.8 million $(72.1 \%)$ of the 5-year growth (difference: $\mathrm{t}=5.39, \mathrm{p}<0.01$ ). Male use increased by 0.5 million, a $38.9 \%$ nominal increase that was not statistically significant $(t=1.86, p=0.063)$. Change in use by age was concentrated in two cohorts, age 25-44 years and age 45-64 years. Among those age 25-44 years, an additional 0.88 million (95\% CI 0.39 million to 1.37 million) reported stimulant use from 2013 to 2018 ( $\mathrm{t}=3.55$, $\mathrm{p}<0.01$ ) or an increase of $85.2 \%$. Among those age $45-64$ years, estimated stimulant use increased by 0.59 million $(\mathrm{t}=3.81, \mathrm{p}<0.01)$ or $100.7 \%$. Among those in the youngest age cohort, age 19-24 years, the initial rate of utilisation in 2013 was the highest of any age group (3.2\%), but the increases were smaller, a nominal increase of $33.4 \%$ that was not statistically significant $(t=0.91, p=0.365)$. Meanwhile, the total adult US population was estimated to increase during the 5-year period from 237.5 million to 248.4 million, an increase of $4.6 \%$.

The growth in stimulant prescriptions was concentrated in the amphetamine products, which were estimated to increase $119.2 \%$ from 10.9 million in 2013 to 23.8 million in $2018(\mathrm{t}=10.46, \mathrm{p}<0.01)$. Growth in use of methylphenidate products was slower, with an estimated $39.4 \%$ increase $(\mathrm{t}=2.27, \mathrm{p}=0.023)$.

\section{Medical conditions}

Stimulant users frequently reported taking medications for a variety of mental, neurological and developmental conditions. The 2018 survey results are shown in table 4 . Among those exposed to the stimulants, $77.8 \% \quad(95 \%$ CI $72.6 \%$ TO $83.0 \%$ ) indicated they took medication for $\mathrm{ADHD}, 26.8 \%$ (95\% CI $22.2 \%$ to $31.5 \%$ ) reported anxiety medication, $25.1 \%$ (95\% CI $19.9 \%$ to $30.3 \%$ ) said they had taken drugs for depression and $15.3 \%$ (95\% CI $9.8 \%$ to $20.8 \%$ ) indicated drug therapy for other mental or neurological conditions. As shown in table 4, similar percentages reported a medical visit for the reported 


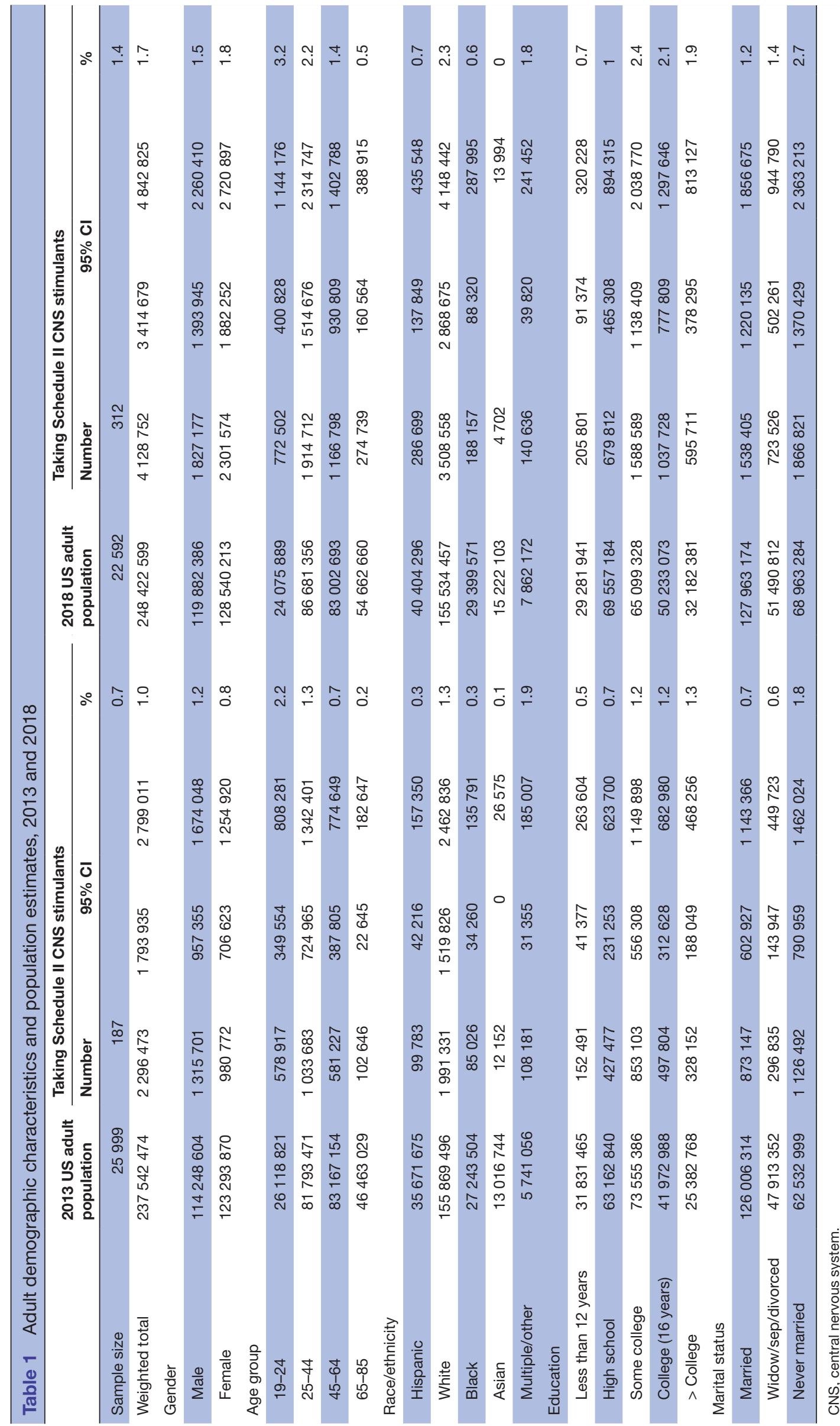




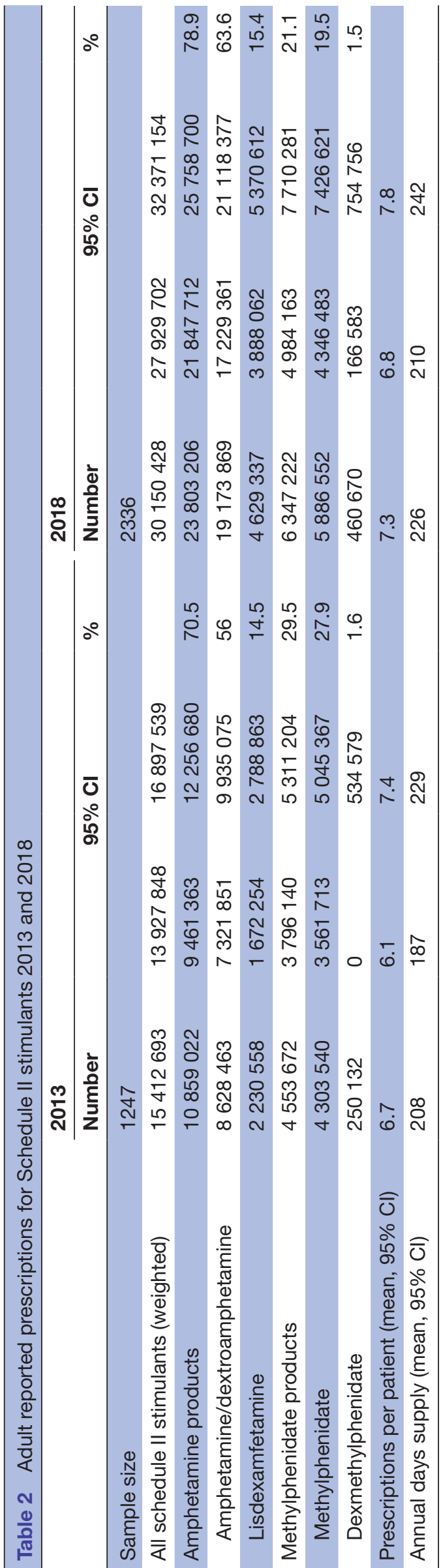

condition and/or indicated a medical condition, regardless of whether it was treated with drugs or a medical visit. Overall, $40.6 \%$ (95\% CI $34.9 \%$ to $46.3 \%$ ) of those reporting stimulant use indicated they were taking medication for anxiety, depression or both.

\section{DISCUSSION}

In this study, we have shown that US adult exposure to prescription CNS stimulants with risk of dependence is substantial—an estimated 4.1 million adults in 2018 - and has grown by approximately $80 \%$ over 5 years. The total number of prescriptions dispensed grew even faster, with an increase of approximately $96 \%$. Medication and treatment for depression, anxiety and other mental conditions were common. Those adults reporting stimulant use represented a population that was younger, had higher educational attainment and was more likely to be unmarried. While use remained more frequent in the youngest age cohort, the largest percentage increases occurred in adults age 25 years and older.

The most frequently reported disorder was ADHD. These data confirm, and extend to more recent years, results of previous studies indicating increasing diagnosis and drug treatment of adults for ADHD covering time periods from 1999 to $2016 .{ }^{21-24}$ One study of adults with ADHD in a large integrated health system also reported high rates of comorbid depression and anxiety. ${ }^{21}$ Another study of ADHD diagnosis and treatment based on office visit data in an earlier 5-year period (2008-2009 to 20122013) reported a $36.4 \%$ increase. $^{24}$ Our analysis differs from these studies in that the primary focus was to assess the exposure to stimulant drugs for any medical purpose, given the varied off-label and on-label uses over many decades.

While we did not assess safety in this study, some patterns of use raise issues that warrant further investigation. Notably, given that amphetamine stimulants are reported to cause anxiety in $10 \%-50 \%$ of patients and methylphenidate in $10 \%-30 \%$ (p. 323), ${ }^{25}$ we observed that anxiety was the second most frequently reported mental condition reported, accounting for $31.2 \%$ of exposed adults. Combination therapy with antidepressants also warrants further investigation given that many antidepressant drugs are associated not only with adverse effects of anxiety and insomnia, but also dullness and flat affect (p. 410). ${ }^{3}$ None of the major antidepressants are FDA approved for use in combination therapy with Schedule II stimulants.

Finally, the growing use of these stimulants should renew interest in updating, characterising and managing the risks of this drug class. There are three concerns warranting investigation. First, these data show that use of CNS stimulants is overwhelmingly in the long term, with a median of 226 days' supply. Second, the skew towards use in younger age groups raises the question of whether or when those prescribed stimulants for ADHD in childhood or adolescence should be discontinued as they grow 
Table 3 Changes in Schedule II CNS stimulant use, 2013 and 2018

\begin{tabular}{|c|c|c|c|c|c|c|c|c|}
\hline & \multicolumn{8}{|c|}{ Persons, number who took CNS stimulants } \\
\hline & 2013 & 2018 & Difference & & $95 \% \mathrm{Cl}$ & $\mathbf{T}$ & $\mathbf{P}$ & Change t1-t2,(\%) \\
\hline All adults & 2296473 & 4128752 & 1832279 & 1006626 & 2657932 & 4.35 & $<0.01$ & 79.8 \\
\hline Male & 1315701 & 1827177 & 511476 & -28416 & 1051368 & 1.86 & 0.063 & 38.9 \\
\hline Female & 980772 & 2301574 & 1320802 & 840273 & 1801333 & 5.39 & $<0.01$ & 134.7 \\
\hline $25-44$ & 1033683 & 1914712 & 881029 & 394685 & 1367372 & 3.55 & $<0.01$ & 85.2 \\
\hline $45-64$ & 581227 & 1166798 & 585571 & 284399 & 886745 & 3.81 & $<0.01$ & 100.7 \\
\hline \multirow[t]{2}{*}{$65-85$} & 102646 & 274739 & 172093 & 35088 & 309099 & 2.46 & 0.014 & 167.7 \\
\hline & \multicolumn{8}{|c|}{ Stimulant prescriptions, number dispensed } \\
\hline $\begin{array}{l}\text { Methylphenidate } \\
\text { products }\end{array}$ & 4553672 & 6347222 & 1793550 & 244341 & 3342759 & 2.27 & 0.023 & 39.4 \\
\hline
\end{tabular}

CNS, central nervous system.

older. Third, while the estimates are not comparable, the major government survey of drug use and mental health for $2018^{26}$ reported that the total number of adults estimated to make non-medical use of CNS stimulants was higher that our total of adults with self-reported medical use. Other studies indicate widespread use in hopes of achieving cognitive enhancement. ${ }^{8}$

This study also has limitations. Although MEPS is the largest publicly available survey providing data on the US use of prescription drugs, our population estimates are derived from two random samples of modest size. A source of potential bias was that utilisation was self-reported and might underestimate true exposure because of possible non-medical use, poor recollection or beginning therapy part way through the survey year. However, most selfreported medications were confirmed in pharmacy records and additional detail about each prescription collected from pharmacy records. While a validation study of this issue reported good agreement between self-reports and pharmacy records, the stimulant controlled substance drugs were not assessed in that study, and agreement could differ. During the period, the US adult population increased by $4.6 \%$, which could contribute to increased use. While we could report the mental and neurological conditions such as ADHD and anxiety and whether medication was prescribed, we could not link these conditions to specific stimulant medications or combinations of medications. The intended medical purpose of various medications was further confounded because some widely used medications are indicated for multiple conditions (eg, paroxetine and sertraline are approved for both depression and social anxiety disorder) and because it is uncertain whether combinations were used intentionally in off-label combinations, or unintentionally.

Table 4 Adult Schedule II stimulant users' mental, neurological conditions, 2018

\begin{tabular}{|c|c|c|}
\hline Reported medication & Reported medical visit* & Reported condition \\
\hline $95 \% \mathrm{Cl}$ & $95 \% \mathrm{Cl}$ & $95 \% \mathrm{Cl}$ \\
\hline
\end{tabular}

\begin{tabular}{|c|c|c|c|c|c|c|}
\hline \multicolumn{7}{|c|}{ Mental, neurological condition } \\
\hline ADHD & 77.8 & 72.6 to 83.0 & 79.3 & 73.3 to 85.4 & 79.3 & 73.3 to 85.4 \\
\hline Anxiety & 26.8 & 22.2 to 31.5 & 31.2 & 26.3 to 36.2 & 31.2 & 26.3 to 36.2 \\
\hline Other mental & 15.3 & 9.8 to 20.8 & 19.8 & 14.3 to 25.3 & 19.8 & 14.3 to 25.3 \\
\hline $\begin{array}{l}\text { Anxiety and/or } \\
\text { depression }\end{array}$ & 40.6 & 34.9 to 46.3 & 45.0 & 39.3 to 50.8 & 45.0 & 39.3 to 50.8 \\
\hline
\end{tabular}

*Medical visit=includes office, inpatient, outpatient or emergency department.

$\mathrm{ADHD}$, attention deficit hyperactivity disorder. 


\section{CONCLUSIONS}

Adult reporting medical use of those stimulants with the highest risk of misuse and dependence increased markedly in 5 years and occurred in a population often reporting multiple neurological or mental disorders. Given that the epidemic in use of prescription opioids continued for years before public health initiatives began to control use, understanding and managing this new resurgence in a class of drugs with a decades-long history of problems should be a public health priority. Physicians seeing patients who request prescriptions for these stimulants should assess with care the risks, benefits and medical need.

Contributors All the coauthors contributed to the study concept and design and to critical revision of the manuscript for important intellectual content. All coauthors have approved the final manuscript. TJM drafted the manuscript and is the guarantor. PWW and TJM provided the statistical analysis. The corresponding author attests that all listed authors meet the authorship criteria and that no others meeting the criteria have been omitted.

Funding The authors have not declared a specific grant for this research from any funding agency in the public, commercial or not-for-profit sectors.

Competing interests All authors have completed the ICJME uniform disclosure form at www.icmje.org/coi_disclosure.pdf and declare GCA is former Chair and a current member of the FDA's Peripheral and Central Nervous System Advisory Committee; is a principal and holds equity in Monument Analytics, a consultancy that provides services to the life sciences industry as well as to plaintiffs in opioid litigation; and is a past member of OptumRx's National P \& T Committee. These arrangements have been reviewed and approved by Johns Hopkins University in accordance with its conflict of interest policies.

Patient and public involvement Patients and/or the public were not involved in the design, or conduct, or reporting, or dissemination plans of this research.

Patient consent for publication Not required.

Ethics approval This study reports deidentified personal data protected by US federal law and published for unrestricted public research use; institutional review board approval is not required.

Provenance and peer review Not commissioned; externally peer reviewed.

Data availability statement Data are available in a public, open access repository. The data for this study are publicly available for research use from the US Agency for Healthcare Research and Quality. https://www.meps.ahrq.gov/mepsweb/ Key SAS code is available upon reasonable request.

Open access This is an open access article distributed in accordance with the Creative Commons Attribution Non Commercial (CC BY-NC 4.0) license, which permits others to distribute, remix, adapt, build upon this work non-commercially, and license their derivative works on different terms, provided the original work is properly cited, appropriate credit is given, any changes made indicated, and the use is non-commercial. See: http://creativecommons.org/licenses/by-nc/4.0/.

\section{ORCID iD}

Thomas J Moore http://orcid.org/0000-0003-0994-836X

\section{REFERENCES}

1 Rasmussen N. America's first amphetamine epidemic 1929-1971: a quantitative and qualitative retrospective with implications for the present. Am J Public Health 2008;98:974-85.

2 Myers RL. The 100 Most Important Chemical Compounds : A Reference Guide. Westport, CT: Greenwood Press, 2007.

3 Brunton L, Knollmann B, Hilal-Dandan R. Goodman and Gilman's The Pharmacological Basis of Therapeutics. New York: McGraw-Hill Education / Medical, 2017.

4 Mayes R, Bagwell C, Erkulwater J. Adhd and the rise in stimulant use among children. Harv Rev Psychiatry 2008;16:151-66.
5 ADDERALL XR. Dextroamphetamine sulfate, Dextroamphetamine saccharate, amphetamine sulfate and amphetamine aspartate capsule, extended release. Lexington, MA: Shire LLC, a Takeda company, 2019.

6 CONCERTA. Methylphenidate hydrochloride tablet, extended release. Titusville, NJ: Janssen Pharmaceuticals, Inc, 2013.

7 VYVANSE. Lisdexamfetamine dimesylate capsule. Lexington, MA: Shire LLC, a Takeda company, 2019.

8 Carlier J, Giorgetti R, Varì MR, et al. Use of cognitive enhancers: methylphenidate and analogs. Eur Rev Med Pharmacol Sci 2019;23:3-15.

9 International Drug Control Conventions. United Nations : Office on Drugs and Crime, 2013. Available: https://www.unodc.org/unodc/en/ commissions/CND/conventions.html [Accessed 14 Dec 2020].

10 Misuse of drugs legislation, 2015. Available: https://www.health-ni. gov.uk/articles/misuse-drugs-legislations

11 Consolidated Federal Laws of Canada. Controlled drugs and substances act. government of Canada justice laws website, 2019. Available: https://laws-lois.justice.gc.ca/eng/acts/c-38.8/ [Accessed 14 Oct 2020].

12 October PS. Australian government federal register of legislation, 2017. Available: https://www.legislation.gov.au/Details/F2017L01285/ Html/Text, http://www.legislation.gov.au/Details/F2017L01285 [Accessed 10 Dec 2020].

13 Controlled Substance Schedules. U.S. department of justice, drug enforcement administration, diversion control division, 2020. Available: https://www.deadiversion.usdoj.gov/schedules/\#define [Accessed 23 Sep 2020].

14 RITALIN. Methylphenidate hydrochloride tablet. East Hanover, NJ: Novartis Pharmaceuticals Corporation, 2019.

15 Medical Expenditure Panel Survey Background. Medical expenditure panel survey, agency for healthcare research and quality, 2019. Available: https://meps.ahrq.gov/mepsweb/about_meps/survey_ back.jsp [Accessed 23 Sep 2020].

16 MEPS HC-204 2018 Full Year Population Characteristics. Medical expenditure panel survey, agency for healthcare research and quality, 2020. Available: https://meps.ahrq.gov/mepsweb/data_stats/ download_data_files_detail.jsp?cboPufNumber=HC-204 [Accessed 3 Apr 2021].

17 MEPS HC-206A: 2018 Prescribed Medicines. Medical expenditure panel survey, agency for healthcare research and quality, 2020. Available: https://meps.ahrq.gov/mepsweb/data_stats/download_ data_files_detail.jsp?cboPufNumber=HC-206A [Accessed 3 Apr 2021].

18 U.S RO. National library of medicine unified medical language system (UMLS) web site, 2018. Available: https://www.nlm.nih.gov/ research/umls/rxnorm/ [Accessed 17 Apr 2018].

19 MEPS Topics: Prescription Drugs. Medical expenditure panel survey, agency for healthcare research and quality, 2019. Available: https:// meps.ahrq.gov/mepsweb/data_stats/MEPS_topics.jsp?topicid=14Z 1 [Accessed 23 Sep 2020].

20 Machlin S, Yu W, Zodet M. Computing standard errors for MEPS estimates. Medical expenditure panel survey, agency for healthcare research and quality, 2005. Available: https://meps.ahrq.gov/ mepsweb/survey_comp/standard_errors.jsp [Accessed 10 May 2021].

21 Chung W, Jiang S-F, Paksarian D, et al. Trends in the prevalence and incidence of attention-deficit/hyperactivity disorder among adults and children of different racial and ethnic groups. JAMA Netw Open 2019;2:e1914344.

22 Zhu Y, Liu W, Li Y, et al. Prevalence of ADHD in publicly insured adults. J Atten Disord 2018;22:182-90.

23 Wei Y-JJ, Zhu Y, Liu W, et al. Prevalence of and factors associated with long-term concurrent use of stimulants and opioids among adults with attention-deficit/hyperactivity disorder. JAMA Netw Open 2018;1:e181152.

24 Fairman KA, Peckham AM, Sclar DA. Diagnosis and treatment of ADHD in the United States: update by gender and race. J Atten Disord 2020;24:10-19.

25 Tisdale JE, Miller DA. Drug-Induced diseases: prevention, detection, and management. 3rd Edition. Bethesda, Maryland: Amer Soc of Health System, 2018.

26 Lipari RN. Key substance use and mental health indicators in the United States: results from the 2018 national survey on drug use and health. Rockville. MD: Substance Abuse and Mental Health Services Administration, 2018. https://www.samhsa.gov/data/sites/default/ files/cbhsq-reports/NSDUHNationalFindingsReport2018/NSDUHNat ionalFindingsReport2018.pdf 